\title{
Aptamers as the Agent in Decontamination Assays (Apta-Decontamination Assays): From the Environment to the Potential Application In Vivo
}

\author{
Mawethu Pascoe Bilibana, ${ }^{1}$ Marimuthu Citartan, ${ }^{1}$ Tzi Shien Yeoh, \\ Timofey S. Rozhdestvensky, ${ }^{2}$ and Thean-Hock Tang ${ }^{1}$ \\ ${ }^{1}$ Advanced Medical and Dental Institute, Universiti Sains Malaysia, 13200 Kepala Batas, Penang, Malaysia \\ ${ }^{2}$ Medical Faculty (TRAM), University of Muenster, Von-Esmarch-Str. 56, 48149 Münster, Germany \\ Correspondence should be addressed to Marimuthu Citartan; citartan@usm.my
}

Received 12 May 2017; Accepted 10 September 2017; Published 26 October 2017

Academic Editor: Xingguo Liang

Copyright (C) 2017 Mawethu Pascoe Bilibana et al. This is an open access article distributed under the Creative Commons Attribution License, which permits unrestricted use, distribution, and reproduction in any medium, provided the original work is properly cited.

\begin{abstract}
The binding specificity and affinity of aptamers have long been harnessed as the key elements in the development of aptamerbased assays, particularly aptasensing application. One promising avenue that is currently explored based on the specificity and affinity of aptamers is the application of aptamers in the decontamination assays. Aptamers have been successfully harnessed as the decontamination agents to remove contaminants from the environment and to decontaminate infectious elements. The reversible denaturation property inherent in aptamers enables the repeated usage of aptamers, which can immensely save the cost of decontamination. Analogous to the point-of-care diagnostics, there is no doubt that aptamers can also be deployed in the point-ofcare aptamer-based decontamination assay, whereby decontamination can be performed anywhere and anytime for instantaneous decision-making. It is also prophesied that aptamers can also serve more than as a decontaminant, probably as a tool to capture and kill hazardous elements, particularly pathogenic agents.
\end{abstract}

\section{Introduction}

Environmental contamination has been a major concern worldwide for the past two centuries [1]. Major environmental contaminants are organic compounds such as small organic and inorganic pollutants, pharmaceuticals, personal care products, toxins of microbial origin, and pathogens [25]. These environmental contaminants have severe impact on quality of food, air, and water, in turn exerting mild to severe deadly effects on human and animals. A range of decontamination methods have been devised to remove environmental contaminants in contaminated soils, leachate, wastewater, and infected tissues [6-8]. General strategies used for removing contaminants from contaminated environment include chemical precipitation, ion exchange, reverse osmosis, and solvent extraction [9]. A novel strategy that is worth venturing into is to use aptamers to remove contaminants in contaminated environments $[10,11]$.
Generated by Systematic Evolution of Ligands by Exponential Enrichment (SELEX), aptamers are short synthetic oligonucleotides, either DNA or RNA, that specifically bind target molecule(s) with high specificity due to their specific and complex three-dimensional shape comprised stems, loops, bulges, hairpins, pseudoknots, triplexes, and quadraplexes [12-14]. Aptamers are able to bind a wide variety of targets from divalent metal ions, small organic molecules, proteins, and cells $[15,16]$. Binding specificity and affinity of aptamers are harnessed in various applications, majorly in biosensing applications $[10,11,17-26]$. Apart from biosensing application, aptamers have also been the subject in the aptamer-based capture assay. In the capture assay applications, aptamers are applied for the purification of their corresponding targets for a wide variety of purposes [11, 27, 28]. The present review seeks to present an overview of the more narrowed context of the aptamer-based capture assay, which is on the usage of the aptamer in the decontaminating process 
or simply abbreviated as apta-decontamination assay. Several aspects of the apta-decontamination assay will be deliberated, which encompasses the functionalization of the aptamer to the usage of the aptamer in decontaminating environment, food sample, and in in vivo application. Reusability of the aptamer and the development of point-of-care aptadecontamination assays are explored before envisaging the potential future trend of the apta-decontamination assay.

\section{Potentiation of the Apta-Decontamination Assays Is Fueled by the Availability of a Large Number of Small Molecule Aptamers}

Most of the contaminants present in the environment are small molecules [29]. Despite the technical challenges in isolating aptamers against small molecules such as the target immobilization and the determination of binding affinities, a significant number of small molecule aptamers were isolated. The availability of a myriad of small molecule aptamers suggests that these aptamers can be used as the corresponding decontaminating agents [28]. One important property of the aptamer that substantiates its role as the decontaminating agent is the exceptional discerning ability of the aptamers even against small molecules. RNA aptamer against theophylline was able to discern against the closely similar molecule, caffeine, that differs from the former by just a methyl group [30]. The aptamer binds caffeine with a binding affinity weaker by 10,000 times compared to that of the theophylline. RNA aptamers were also able to distinguish between various $\mathrm{L}$ and $\mathrm{D}$ amino acids $[31,32]$.

\section{Functionalization of Aptamers for Biodecontamination}

Akin to the capture assay application as reviewed by Citartan et al. [27], the very first step for the application of the aptamers for the biodecontamination is the immobilization of the aptamers on the surface of the platforms. To enable this immobilization, aptamers are first functionalized with specific functional groups (e.g., thiol, amine, and biotin) $[22,33]$. Interaction of these functional groups with the functional groups on the surface of the platforms immobilizes the aptamer. Typical functionalization strategy is by appending amine groups at the aptamer termini $\left(5^{\prime}\right.$ or $3^{\prime}$ end), which can form peptide bond with the carboxyl groups on the surface of the platform. The carboxylated surface is first subjected to N-hydroxysuccinimide (NHS)/1-Ethyl-3-[3dimethylaminopropyl] carbodiimide hydrochloride (EDC) solution activation to form active NHS ester that can react with the primary amines. Peptide bond-mediated conjugation of the aptamer on the platform surface was adopted by Dong Huy et al. [34], in which the anti-17 $\beta$-estradiol (E2) aptamers used were appended with primary amines. The glass microbeads were first amino-silane modified and then treated with phenylene diisothiocyanate (PDITC) to generate the isothiocyanate-modified bead, in which the active isothiocyanate group can react with the amine-functionalized anti E2 aptamer. Chen et al. [35] have fabricated a hepatitis C virus- $(\mathrm{HCV}-)$ specific aptamer conjugated with amine to react with the sepharose 4 Fast Flow (4FF) beads to immobilize the aptamer. The carboxylated-derivative sepharose 4FF beads, which is $4 \%$ highly cross linked spherical sepharose is activated via NHS/EDC prior to peptide bond formation with the amine-terminated aptamers (Figure 1(a)).

For immobilizing aptamers, nanoparticles are also employed as the platform, which have more surface area to volume ratio for the immobilization of aptamers [36]. Hu et al. [37] have conjugated amine-functionalized aptamer on the surface of nanoparticles that contain a stable poly (lactic acid)-polyethylene glycol (PLA-PEG) block copolymer with a terminal carboxylic acid functional group (PLAPEG-COOH) (Figure 1(b)). The carboxylic acid functional groups form peptide bond with the primary amines. This immobilizes the aptamers, which were used for the decontamination of mercury $\left(\mathrm{Hg}^{2+}\right)$ in vivo. It was also found out that Metal-Organic Frameworks (MOFs) as the platform also has high surface area that can accommodate more aptamers [38]. In one study, MOFs were generated which comprise $\mathrm{Fe}_{3} \mathrm{O}_{4}$ nanoparticles encapsulated with a polydopamine layer which was then functionalized on the surface with UiO-66-amine [39]. However, to form a covalent bond between the amine-conjugated aptamer and the UiO66-amine, glutaraldehyde linker was used. The aptamer was applied for the decontamination of polychlorinated biphenyls in contaminated soil samples.

Another alternative to conjugate directly to the amineconjugated aptamers is to use Cyanogen-bromide $(\mathrm{CNBr})$ activated crosslinker. $\mathrm{CNBr}$ reacts with the hydroxyl group to generate cyanate esters or imidocarbonates, which can readily react with primary amines-containing molecules. Madru et al. [40] covalently immobilized anticocaine aptamer conjugated amine on $\mathrm{CNBr}$-activated sepharose. However, there is growing concern associated with high toxicity of $\mathrm{CNBr}$ and its potentiality as an environmental pollutant [41]. In addition, surface immobilization of $\mathrm{CNBr}$ is time consuming, which may inactivate the biological activity of aptamer. Biotin-streptavidin interaction is also used for aptamer immobilization although the interaction is less strong than the peptide bond. However, the biotin-streptavidin interaction is rapid and stable over a wide range of $\mathrm{pH}$ values and temperatures [42]. The isoelectric point of streptavidin is 6.8 to 7.5 , which minimizes nonspecific adsorption within this $\mathrm{pH}$ range. Biotinylated arsenate $(\mathrm{As}(\mathrm{V} / \mathrm{III}))$ aptamers functionalized on the surface of streptavidin agarose resin were used to completely remove As(V/III) in the aqueous solution [43]. After the completion of the aptamer immobilization via all the strategies, the unconjugated aptamers should be removed from the immobilization surface. This is important as carry-over of these unreacted aptamers into the "targetcapturing process" may result in nonconjugated aptamertarget formation. If this happens, the decontamination capacity of the immobilized aptamers is reduced.

\section{Aptamers as the Pollutant Absorbent in the Environment}

Decontamination process is traditionally achieved by chemical precipitation, ion exchange chromatography, and other 


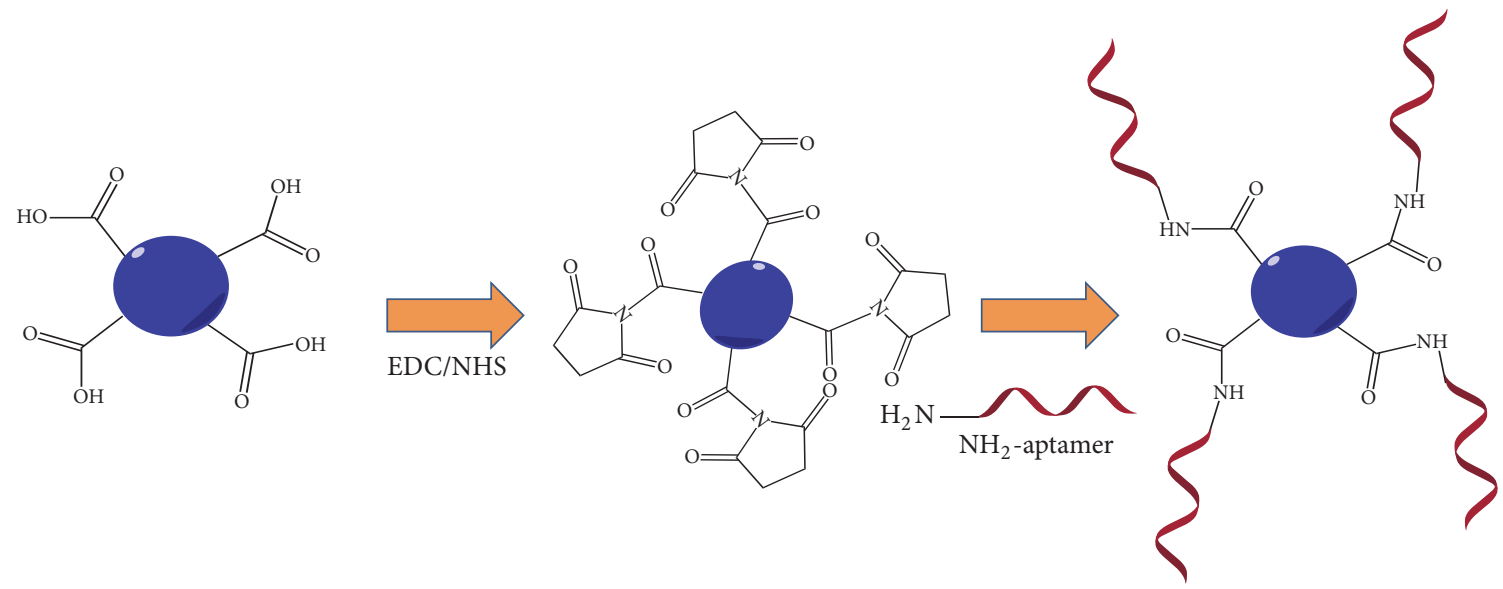

(a)
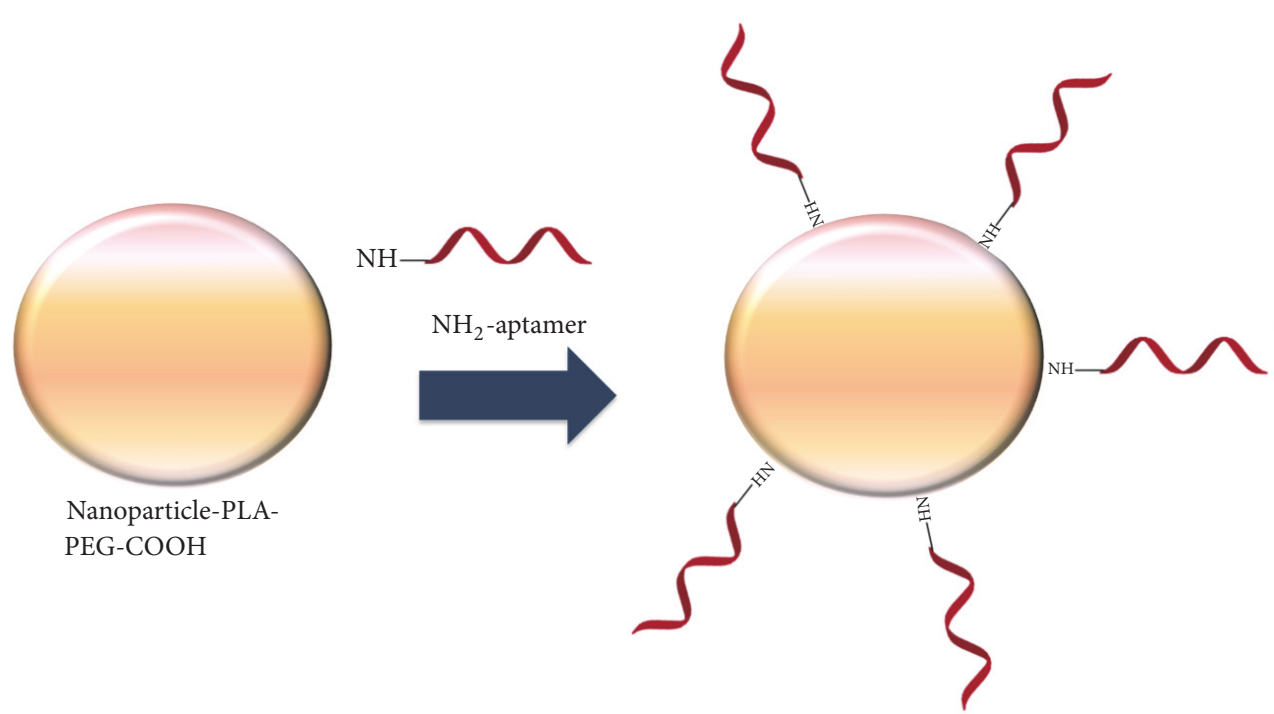

(b)

FIGURE 1: (a) Schematic representation of the conjugation of the amine-terminated aptamer on the surface of the carboxylated-functionalized sepharose 4FF beads via NHS/EDC activation [35]. (b) Conjugation of the amine-functionalized aptamer on the surface of nanoparticles that contain a stable poly (lactic acid)-polyethylene glycol (PLA-PEG) block copolymer with a terminal carboxylic acid functional group (PLAPEG-COOH) [37].

methods [9]. However, these are inexpensive and it is not feasible to reduce their concentrations to the levels as low as that required by the environmental legislation [44, 45]. A very wise alternative is to use aptamers as the pollutant absorbents, for binding and removing the environmental contaminants. Moreover, aptamer-based adsorption does not result in any secondary pollution as no harmful substances are produced during the process. One example of aptamer used in the apta-decontaminant assay is the DNA aptamer against arsenite $[\mathrm{As}(\mathrm{III})]$ and arsenate $[\mathrm{As}(\mathrm{V})]$. Kim et al. [43] developed a novel apta-decontamination method for the complete removal of 28.1 to $739.2 \mu \mathrm{g} \mathrm{L}^{-1} \mathrm{As}(\mathrm{III})$ and As(V) from the groundwater after just $5 \mathrm{~min}$ of incubation with its corresponding aptamer. Complete removal of the target can be achieved in a very short time due to the fast on and off binding kinetics of the aptamer with the target. In a similar manner, Hu et al. [46] have developed an aptadecontamination assay that is able to decontaminate organic contaminants such as cocaine and diclofenac at $\mathrm{ng} \mathrm{L}^{-1}$ levels in drinking water (Figure 2). In fact, As(III) and As(V) aptamer column have a better decontamination efficiency compared with the other filtration technology as demonstrated by Hsieh et al. [47] on their electro-ultrafiltration system. The electro-ultrafiltration system has a cut-off value of $100 \mathrm{kDa}$ and requires the use of electrical voltage of $25 \mathrm{~V}$ to achieve $\mathrm{As}(\mathrm{III})$ and $\mathrm{As}(\mathrm{V})$ decontamination efficiency of $79 \%$ in groundwater samples [43]. It is manifested that the apta-decontamination assay requires no electricity and is 


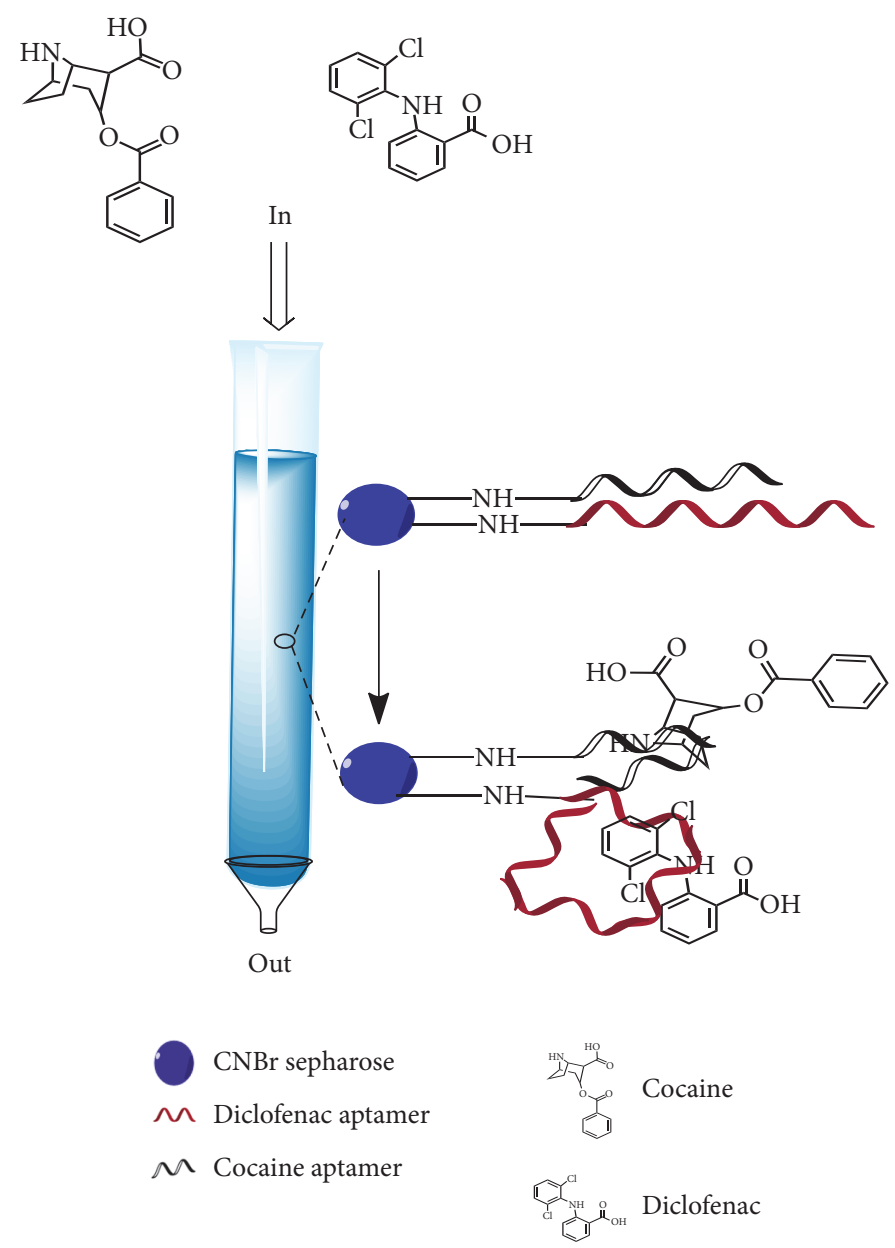

FIGURE 2: Illustration of apta-decontamination of cocaine and diclofenac. In this assay, aptamer against cocaine and diclofenac are immobilized on the resin within a column for the decontamination of cocaine and diclofenac [46].

more specific than the nonspecific nature of the ultrafiltration system that relies on molecular-weight cut-off value to decontaminate target.

Ion exchange system is based on the reversible chemical reactions for removing dissolved ions from solution and replacing them with other similarly charged ions $[48,49]$. It is timely to mention that, due to higher selectivity and affinity of the aptamer against the target ion, apta-decontamination assay could potentially replace or complement ion exchange system in decontamination. As a proof-of-concept, aptamer against uranyl ion was used for the decontamination of uranium. Uranium contaminated drinking water is a common problem resulted from radioactive disposal waste [50]. Kim et al. [51] have immobilized thiolated aptamer against uranyl ion on the surface of the sulfo-SMCC (sulfosuccinimidyl 4-(N-maleimidomethyl)cyclohexane-1-carboxylate)activated aminopolystyrene resin as the solid support. The decontamination assay is able to decontaminate $0.63 \mathrm{mg}$ of uranium amidst the presence of the other multiple ions in the sample [51]. Aptamer as the decontaminating agent is also able to discriminate between closely similar molecules and is very selective against the target. Recent study has shown the RNA aptamer that selectively adsorbs traces ( $\mathrm{n} \mathrm{L} \mathrm{L}^{-1}$ ) of microcystin-LR (MC-LR) in drinking water [52], discriminating against microcystin-RR, microcystin-LW, and nodularin which are cyclic pentapeptides that have a similar structure with MC-LR. This aptamer could be used as the decontaminating agent to remove MC-LR. MC-LR is a potential carcinogen for animals and humans that is present in aquatic environment $[53,54]$.

Isolation of aptamers against bacterial surface proteins or against the whole-cell [55] permits their application in removing bacteria from the environment. Song et al. [56] used three different aptamers selected using a bacterial cell-SELEX that have different affinities and target different proteins on surface of Escherichia coli (E. coli). The target proteins may be components such as Lipopolysaccharide (LPS), outer membrane proteins, and flagella, which must be confirmed by aptamer-facilitated biomarker discovery (AptaBiD) [57]. These amino-modified aptamers were immobilized on the surface of $\mathrm{TiO}_{2}$ for targeted and enhanced disinfection of E. coli (Figure 3). The target E. coli was approximately $99 \%$ inactivated under UV irradiation in 30 min. The assay was also specific and selective, as it inactivates 

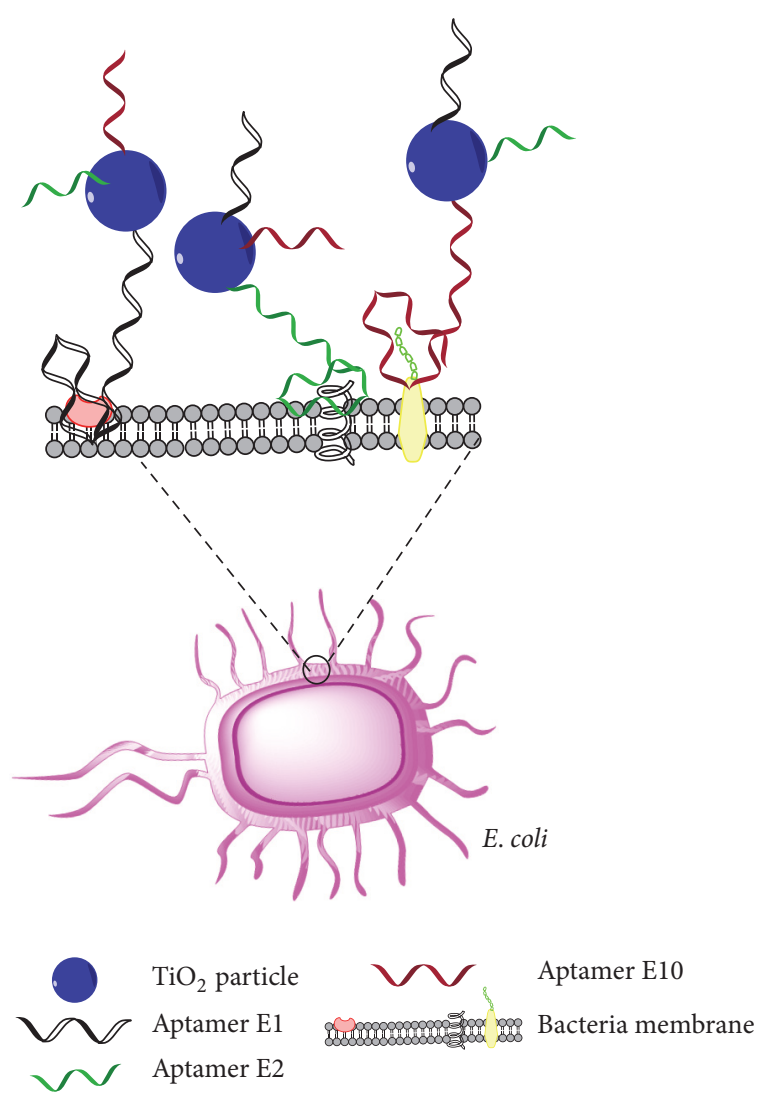

FIGURE 3: Schematic diagram of apta-decontamination of bacteria. Three aptamers specific against three different bacterial surface proteins were immobilized on surface of $\mathrm{TiO}_{2}$ to specifically capture E. coli, which is then deactivated under UV irradiation [56].

only E. coli in the presence of a mixed culture (E. coli and Staphylococcus epidermidis). Besides bacteria, aptamers were also used to remove contaminating bacteria toxins from soil, food, and water environment $[9,58]$.

In general, a cause for concern is the difference in the ionic strength/pH of the aqueous environmental target from the optimal buffer used for the aptamer interaction that could debilitate its binding affinity. To address this problem, aptamers should be placed in a distinct compartment to thwart them from being affected by surroundings that will undermine their binding capacity. As such, liposomes that contain the aptamer binding buffer could be possibly used as the holding moiety for aptamers. Kim et al. [59] have constructed biocomposite material that comprise liposome that contains aptamers dissolved in the binding buffer for the selective and simultaneous decontamination of E2, bisphenol A (BPA), and oxytetracycline from the contaminated water within 30 minutes (Figure 4). The capturing efficiency is higher (more than $80 \%$ ) when liposomes are used as the holding moiety as compared to the DNA aptamers in water. The cases enumerated are sufficient to imply that the aptadecontamination assay could potentially replace or complement the current existing strategies in decontaminating small molecules in the environment.

\section{Apta-Decontamination Assay on Food Sample}

Besides, majorly in the environment, the capturing capacities of the aptamers are also exploited to remove contaminants from food sample. Most of the apta-decontamination assays on food sample reported so far revolve only around ochratoxin A (OTA) aptamer, isolated by Cruz-Aguado and Penner [60], with the estimated dissociation constant $\left(K_{d}\right)$ of $360 \mathrm{nM}$. They have developed the first aptamer-based affinity column for the concentration and decontamination of OTA. The OTA aptamers were conjugated to agarose resin and were packed into a pipette tip, which was used as the column. The performance of the affinity column-functionalized aptamer was first tested with a buffer spiked with OTA, whereby more than $97 \%$ of OTA was removed from $1 \mathrm{~mL}$ of a $100 \mathrm{nM}$ OTA solution. Subsequently, the apta-decontamination assay of OTA was further coupled with fluorescence detection for the better monitoring of the OTA removal. In this study, Yang et al. [61] developed an aptamer affinity column with ultrahigh performance liquid chromatography coupled with fluorescence detection to remove OTA from ginger powder. The amount of OTA removed from the ginger powder ranged from 1.51 to $4.31 \mu \mathrm{g} \mathrm{kg}^{-1}$, which was lower than the European Union regulatory limits. Average recovery of 85.36-96.83\% was acquired for blank samples spiked with OTA at 5, 15, and $45 \mu \mathrm{g} \mathrm{kg}^{-1}$.

The OTA removal was also facilitated with the use of magnetic field mediated by magnetic nanoparticles, which can offer higher capturing efficiency with shorter diffusion time. Wu et al. [62] have immobilized OTA aptamers on the surface of the magnetic nanospheres and have developed a magnetic solid phase extraction procedure to remove OTA from the food samples. The assay developed consists of high performance liquid chromatography separation and a fluorescence detection (HPLC-FD) system [62]. The clean-up of the OTA was facilitated by magnetic field and the removal of OTA was monitored by HPLC-FD. With $2.5-50 \mu \mathrm{g} \mathrm{kg}^{-1}$ of OTA spiked in different samples of cereals products and wheat flour spiked, the recoveries varied from 67 to $90 \%$. The apta-decontamination assay showed a high selectivity in comparison to a conventional hydrophobic sorbent, with a good extraction recovery. However, as observed in the case study by Schax et al. [10], using OTA, the binding capacity of the aptamer against the corresponding targets is diminished in complex sample. Thus this strongly suggests that during in vitro selection, complex media could be used as the SELEX binding buffer. The complex media, which are optimal for the aptamer performance, will ensure that the aptamer binding is retained during the decontamination process. Moreover, Sefah et al. [63] have shown that the in vitro selection carried out in culture media Dulbecco's phosphate-buffered saline as the SELEX binding buffer is still be able to produce aptamers that bind target in the similar buffer.

Apta-decontamination system enables specific extraction of toxins or natural compounds from turbid matrices in a one-step procedure. Rouah-Martin et al. [64] have developed apta-decontamination of ergot alkaloids (causing 


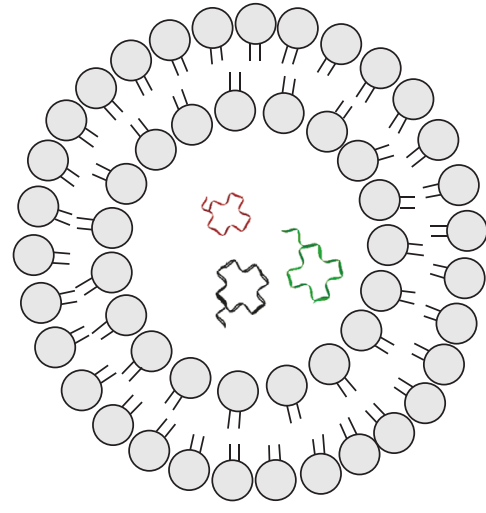

Liposome containing aptamers suspended in buffer
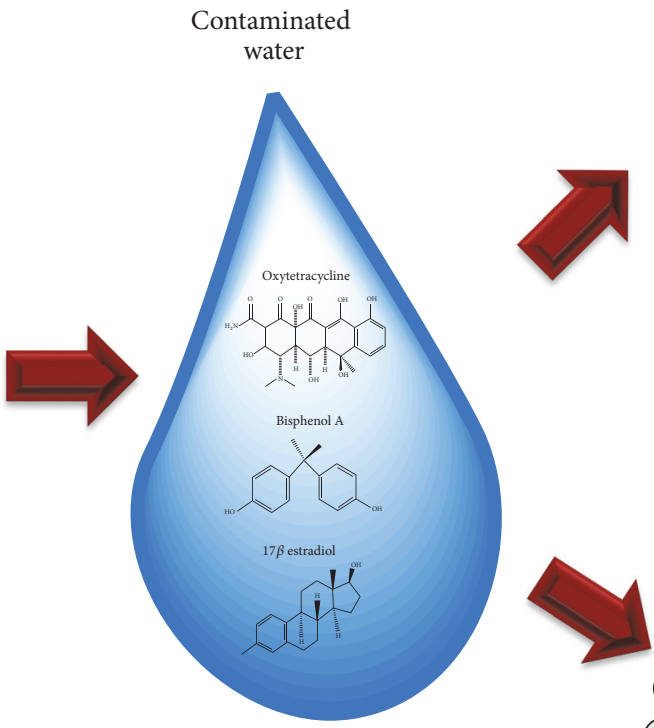
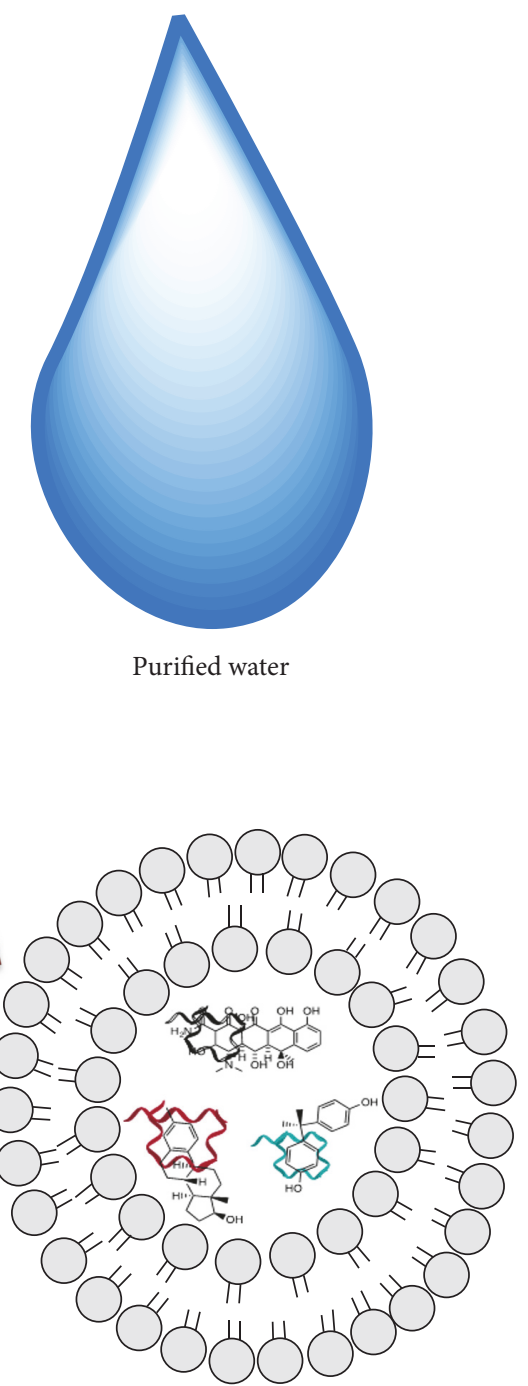

Contaminants captured by the aptamers within liposome
Water
ר $17 \beta$ Estradiol aptamer
N Oxytetracycline aptamer
N Bisphenol A aptamer

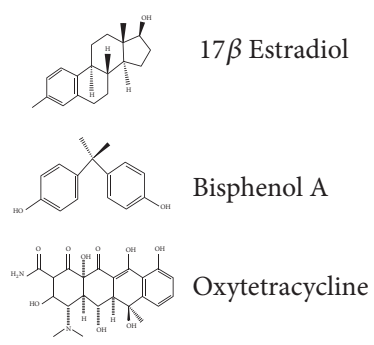

Liposome

FIGURE 4: Illustration of apta-decontamination using liposome containing aptamer. Liposomes that contain the aptamer binding buffer also comprise aptamers that are specific against $17 \beta$-estradiol (E2), bisphenol A, and oxytetracycline. These aptamers bind the contaminants (17 $\beta$ estradiol (E2), bisphenol A, and oxytetracycline) and remove them from the contaminated water source [59].

severe poisoning known as ergotism), using DNA aptamerbased ergot alkaloids immobilized on silica for specific solid phase extraction system. The assay enables specific extraction of ergot alkaloids from a contaminated rye feed sample prior to the analysis of the extract using liquid chromatography quadrupole-time-of-flight mass spectrometry. The success manifested by the OTA and ergot alkaloids aptamers may further fuel the isolation and subsequent 
application of the aptamers against contaminants in the food product.

\section{Aptamers as the Potential In Vivo Decontamination Agent}

High specificity conferred by aptamers with minimal offtarget binding accounts for its wide application in the fields of drug delivery, therapeutic agent, molecular biosensing, and biomimetic engineering [17, 65-70]. This also strongly insinuates that aptamers can also be potentially used to decontaminate contaminants in vivo $[27,35]$.

Aptamer-based decontamination assay is used to selectively capture and detoxify infectious agents. In one study, Chen et al.[35] used HCV-specific single-stranded DNA aptamers to decontaminate approximately $80 \%$ of the HCV from human plasma samples. This novel aptadecontamination procedure could effectively remove HCV particles and likely to serve as a novel therapy option for HCV. Proske et al. [71] have used nuclease-resistant $2^{\prime}$ amino-2'-deoxypyrimidine-modified RNA aptamers (DP7) that recognize a peptide comprising amino acid residues (90-129) human prion protein with high specificity. This particular region is important for the conversion of $\operatorname{PrP}(\mathrm{C})$ into its pathogenic isoform $\operatorname{PrP}(\mathrm{Sc})$. This aptamer results in the reduction of $\operatorname{PrP}(\mathrm{Sc})$ accumulation in prion-infected cells. The DP7 aptamer may open the door towards using aptamers as a rational therapeutic of transmissible spongiform encephalopathies.

The high stability and less immunogenicity associated with aptamers potentiate aptamers for the selective capturing and eliminating a circulating tumor cells. Li et al. [67] presented a study that makes use of hydrogel functionalized with two layers with the top one containing DNA aptamer specific against human precursor T-cell acute lymphoblastic leukemia cells (CCRF-CEM), while the bottom one contains doublestranded DNA as the "affinity tag" for the intercalation of doxorubicin to eradicate target circulating tumor cells. The aptamer on the top hydrogel layer was able to capture CCRFCEM cells with high efficiency and specificity, while the doxorubicin sequestered at the bottom is released to kill tumor cells. Moreover, Li et al. [72] developed an endonucleaseresponsive circulating tumor cells aptamer that was functionalized on hydrogels for the specific catch and nondestructive release of rare circulating tumor cells. The aptamer was hybridized to another sequence that is immobilized on the surface of the hydrogel. Both the sequence immobilized on the surface of the hydrogel and the aptamer sequence harbour restriction endonuclease cleavage site, targeted by BamHI. The cells captured by the aptamers will be released after the cleavage of the restriction sites (Figure 5). Specificity of the assay is also substantiated as the assay developed showed binding of CCRF-CEM cells rather than Ramos cells on the hydrogel surface. The capture and release of circulating tumor cells can be used for decontamination and for the detailed analysis of circulating tumor cell properties [72]. Reports found out that chemotherapeutic agents such as cisplatin or $5 \mathrm{FU}$ increase the amount of heat shock protein 70 (HSP70) exosomes, which then activates myeloid-derived suppressive
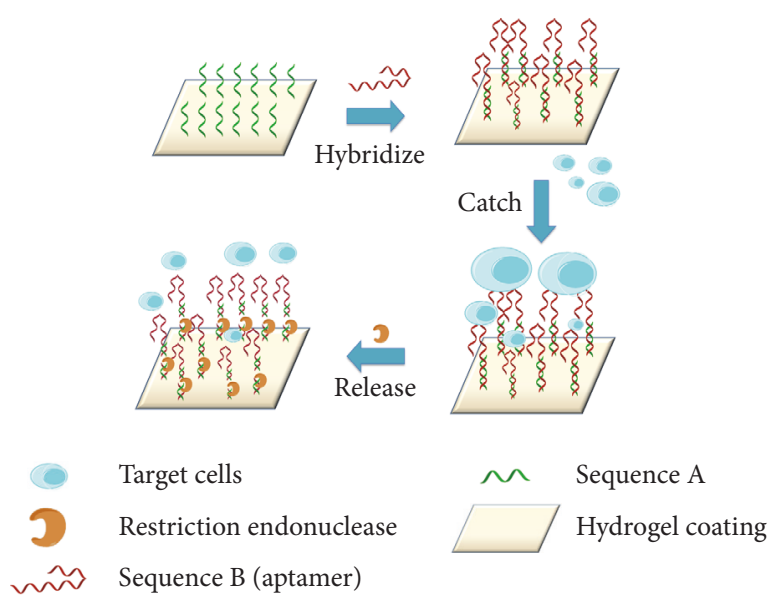

FIgURE 5: Schematic diagram of an application of aptamer in capturing and releasing tumor cells. Sequence immobilized on the surface of the hydrogel forms a duplex with an aptamer sequence. Cleavage of the restriction sites on the aptamer (sequence B) and the immobilized sequence (sequence A) releases the target cells. Endonuclease cleaves the phosphodiester bond within the aptamer, resulting in the loss of its anchoring to the target cells. Subsequently, the target cells are dissociated from the aptamer and released [72].

cells (MDSCs) obstructing the development of an antitumor immune response [73]. Exosomes through HSP70 expressed in their membrane then interact with the toll-like receptor 2 (TLR2) to activate MDSCs. Gobbo et al. [74] reported the capturing application of the peptide aptamer that binds to the extracellular domain of membrane HSP70 and to capture HSP70 exosomes from cancer patient samples. The aptamer is able to block the interaction between HSP70 and TLR2, suppressing the activation of the MDSCs. In fact, aptamers can be a promising class of molecules for decontaminating contaminants in vivo owing to high selectivity and their superior characteristics of high cell penetration capacity.

\section{Reusability of Aptamers as the Decontaminating Agents}

An ideal criterion of a decontamination assay is reusability, which can be conveyed by aptamers that have reversible denaturation property $[75,76]$. Reusability of the aptamer refers to the repetitive usage of aptamers in binding and eluting their corresponding targets with minimal loss of capturing efficiency. Aptamers can be denatured and renatured to their original conformations by changing the temperature and $\mathrm{pH}$. Recently, Hu et al. [46] appraised the reusability of an aptamer-based column in removing cocaine and diclofenac from the drinking water. Decontamination capacities of the aptamers were evaluated before and after 30 days at $4^{\circ} \mathrm{C}$ and were found to decrease by only $1.2-4.7 \%$. Moreover, the regeneration of the aptamer-based column was achieved by simple washing with pure water at a rate of $10 \mathrm{~mL} \mathrm{~min}^{-1}$ at $50^{\circ} \mathrm{C}$ for $5 \mathrm{~min}$. The decontamination capacity of the aptamer column decreased approximately by $10 \%$ after 10 regeneration cycles, corroborating that covalent binding between aptamers 

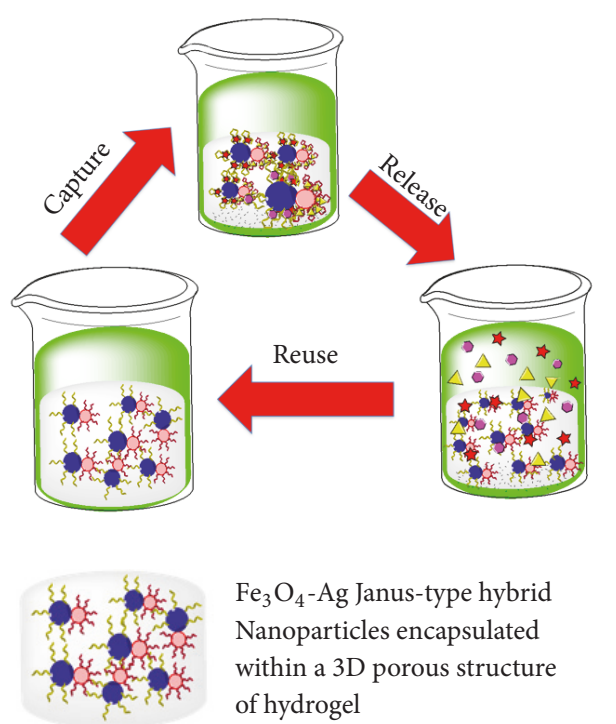

$\mathrm{Fe}_{3} \mathrm{O}_{4}$-Ag Janus-type hybrid Nanoparticles encapsulated within a $3 \mathrm{D}$ porous structure of hydrogel

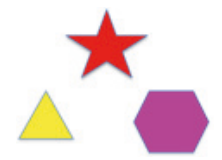

Mixture targets (heavy metal ions, organic pollutants, and pathogens)

FIGURE 6: Schematic representation of the reusability of aptamerbased hydrogel scavenger in apta-decontamination of three pollutants. Aptamers are immobilized on the surface of the $\mathrm{Fe}_{3} \mathrm{O}_{4}$ Ag Janus-type hybrid nanoparticles encapsulated within a 3D porous structure of hydrogel. The targets (heavy metal ions, organic pollutants, and pathogens in drinking water) are captured by the aptamers. Aptamers are reused/regenerated by changes in the $\mathrm{pH}$ and the aptamers can be reused for the subsequent capture assay [77].

and $\mathrm{CNBr}$-sepharose is stable despite using hot water. Using a similar approach of regeneration, $\mathrm{Hu}$ et al. [52] have "regenerated" MC-LR aptamer functionalized on surface of RNA-graphene oxide with hot water and their aptadecontamination capacity reduced by about less than $10 \%$ after 5 cycles. Schax and coworker [10] tested the reusability of OTA aptamer-based column for 4 additional cycles of decontamination within 20 days. In between the decontamination cycles, the aptamer-based column was washed with binding buffer to ensure refolding of the aptamer followed by storage at $4^{\circ} \mathrm{C}$ in binding buffer. The aptamer remained stable for a period of 20 days, and the amount of OTA obtained did not change profoundly, between 84 and $94 \%$ for all the cycles, with elution efficiency between 71 and $84 \%$. Wang et al. [77] reported $a$ hydrogel scavenger containing aptamers immobilized on $\mathrm{Fe}_{3} \mathrm{O}_{4}$-Silver ( $\mathrm{Ag}$ ) Janus-type hybrid nanoparticles encapsulated within a $3 \mathrm{D}$ porous structure of hydrogel for high efficiency of simultaneous decontamination of $\mathrm{Hg}^{2+}$ (99.96\%), BPA (98.9\%), and E. coli (100\%) in drinking water as showed in Figure 6. Regeneration is achieved based on the changes in the $\mathrm{pH}$, whereby the hydrogel scavenger was washed with $\mathrm{HCl}(\mathrm{pH} 1)$ and water three times. In almost all the cases mentioned, the efficiency of the aptamers remains the same after several cycles of decontamination, which demonstrates the excellent reusability property of the aptamer. Another elution strategy is based on the usage of the chelating agent, which chelates the divalent ions that are important for the binding affinity of the aptamer against the target. In the presence of the chelating agent that chelates the divalent ion, the target is released from the aptamer. This is because the aptamer is unable to retain the structural conformation without the presence of the divalent ion. In one surface plasmon resonance analysis that aims to look at the significance of the calcium $\left(\mathrm{Ca}^{2+}\right)$ ion for the interaction between the RNA aptamer and its corresponding target human immunoglobulin (IgG1), addition of ethylenediamine tetra-acetic acid (EDTA), which chelates the $\mathrm{Ca}^{2+}$, results in the loss of the binding affinity between these two molecules. However, the affinity is regained upon the addition of the ion. It can be surmised that the chelating agents can be used for the elution of the target [78]. Integration of the aptamer into the decontamination assay can immensely save cost. The overall cost of manufacturing aptamer is plummeting, which is also influenced largely by the increasing demand for oligonucleotides that accounts for the reduction in the cost of nucleotide phosphoramidites. For one gram of DNA phosphoramidites, the estimated cost is less than US\$3, while that for per gram of $2^{\prime}$-fluoro, $2^{\prime}$-ribo, and $2^{\prime}$-O-methyl RNA phosphoramidites costs less than US\$20 [79].

\section{Chemical Modifications for the Enhanced Stability of the Aptamer}

During the apta-decontamination process, the most prominent challenge is to stabilize or protect the aptamers (especially RNA aptamers) from the degradation action of the nucleases that are present in the environmental soil and water. Stability can be achieved via modification of the aptamer following isolation by SELEX. However, due diligence should be practiced as POST-SELEX modification may impair the binding affinity of the aptamer against the target [80]. Hence, it is desirable to incorporate the chemical modification into the library used for the in vitro isolation of the aptamers. Modification includes the addition of cap at the $3^{\prime}$ - and/or $5^{\prime}$ - ends to occlude the exonuclease degradation action [81]. Stability of the aptamers can also be enhanced by using phosphorothioate nucleotides [82]. Another modification is Locked nucleic acids (LNAs), whereby the $2^{\prime}-\mathrm{O}$ is linked to the $4^{\prime}-\mathrm{C}$ of the ribose via a methylene bridge, giving rise to $3^{\prime}$-endo conformation that is stable against the action of nucleases [83, 84]. A highly nuclease-resistant aptamer, Spiegelmer, a mirror-image aptamer built from nucleotides of the nonnatural L-chirality, can be a perfect candidate for decontamination. As these L-aptamers are mirror images of the natural D-aptamer counterpart of the same sequence, the former is unrecognized by the stereoselective nucleases. Consequently, spiegelmers are highly resistant to the action of nucleases [85]. Modification is also achievable by substituting hydroxyl group at the $2^{\prime}$-position of the ribose sugar with the amino $\left(\mathrm{NH}_{2}\right)$, fluoro (F), alkyl, and thio groups [86]. 


\section{Point-of-Care Aptamer-Based Decontamination Assay}

The diagnostic technology has moved into another dimension, whereby the diagnostic can be performed anywhere with a fast turnaround time that enables quicker treatment, known as the point-of-care testing [87]. Analogous to a point-of-care diagnostic assay, an apta-decontamination assay should also be developed on a similar basis, so that the decontamination can be carried out anytime that could permit instant decision-making. Fueled by the need to avoid health hazards, ecosystem, food, and water contaminated by a variety of microbial pathogens, toxins, heavy metals, organic pollutants, and adulterants should be subjected to decontamination before reaching consumers [88]. The ideal point-of-care aptamer-based decontaminating device should be of low power, low cost, reusable, provide durability, and have a high apta-decontamination capacity without any secondary pollution in purifying environmental pollutants. A point-of-care assay developed by Wang et al. [77] exhibited the ideal application of a novel apta-decontamination, which consists of an empty filter unit of a commercially available water purifier. The water purifier is packed with hydrogel scavenger that accommodates multiple aptamers that can capture pollutants. The hydrogel scavenger also holds $\mathrm{Fe}_{3} \mathrm{O}_{4}-$ Ag Janus nanoparticles functionalized with multiple aptamers to remove metal ions, organic pollutants, and pathogens simultaneously. This apta-decontaminant showed an outstanding performance in reducing $\mathrm{Hg}^{2+}$ concentration from $1 \mathrm{ppm}$ to levels lower than $1.1 \mathrm{ppb}$ and BPA from $60 \mathrm{ppm}$ to level smaller than $0.8 \mathrm{ppm}$ and can effectively destroy more than $99.998 \%$ of $E$. coli simultaneously. This aptamerbased decontamination device can remove three different elements simultaneously, suggesting that multiple aptamers can be used in future for the removal of a myriad of major environmental contaminants. The study carried out could provide an impetus to expedite the development of point-ofcare apta-decontaminating device that is mobile and with a platform that is immobilized with multiple aptamers that are specific against different targets.

\section{Conclusion and Future Perspective}

Despite great promise, there are major barriers that must be transcended to use aptamers as decontamination agents. Biostability of aptamers is one of the concerns that currently limits the application aptamers as decontamination agents in the real world [89]. Therefore, to generate aptamers with proved biostability, a direct evolution of a nuclease-resistant sequences from a library of different chemical substituents should be carried out [90,91]. Another critical factor that must be heeded is the compatibility of the aptamer with the environmental condition which the aptamer is subjected to during decontamination process. Metal cation concentration, buffer conditions, and temperature are the main elements that influence the stability and affinity of the aptamers [92, 93]. The best approach is to mimic the actual environmental condition by which the aptamer is exposed to at the point of capturing process in the SELEX process itself. As such, aptamers that can optimally perform during the capture process can be successfully isolated [94].

Aptamers are quite flexible in the functionalization, thermodynamically stable, and able to bind target within a short period of time and are also stable despite repetitive usage. Endowed with these excellent properties, aptamers have "fared well" in decontaminating environment, food sample, and removing infectious agents, which is also supported by the availability of aptamers against a number of small molecular contaminants. Thus, it is felicitous to say that the apta-decontaminating assay should not merely be applicable for decontamination, but also be focused towards capturing and removing hazardous agents. One case study is exhibited by Ranjbar and Hafezi-Moghadam [95] who have designed a MPT64 antibody aptamer-based DNA nanorobot. The lock is constituted by the duplex formation between the aptamer sequence and the complementary strand. In the presence of the target, the aptamer strand binds to it, opening up the lock, releasing the drug molecules from the nanorobot that can interact with the bacterial surface protein. It is worth noting that DNA origami structure, which is a long singlestranded scaffold that could be moulded into any intended configurations using short ssDNA as the connectors [96, 97], could serve as a powerful smart material in the future that could assist the aptamers to capture and eradicate bacteria as well as virus-infecting eukaryotic cells. Inspiration can also be derived from Douglas et al. [98] who have fabricated DNA nanorobot by using DNA origami technology that is programmed to independently recognize target defected cells and deliver payloads. Aptamers specific against any targets can be infiltrated into the DNA origami and the whole ensemble can be adopted for targeted elimination of the bacteria. The application of DNA origami can be extended towards the simultaneous decontamination of a panel of contaminants in water via the usage of the corresponding specific aptamers. Multiple aptamers can be conjugated to the ssDNA constituents of the DNA origami and binding against their cognate targets may induce conformational change that can facilitate capturing and removal of the target.

\section{Conflicts of Interest}

The authors declare that they have no conflicts of interest.

\section{Acknowledgments}

Mawethu Pascoe Bilibana was supported by University Sains Malaysia (USM) Postdoctoral Fellowship. M. Citartan and T.-H. Tang were supported by a FRGS Grant (203/CIPPT/ 6711441), an E-science Grant (305/CIPPT/613235), and a USM Research University Grant (1001.CIPPT.811317).

\section{References}

[1] P. Karrari, O. Mehrpour, and M. Abdollahi, "A systematic review on status of lead pollution and toxicity in Iran; Guidance for preventive measures," DARU, Journal of Pharmaceutical Sciences, vol. 20, no. 1, article 2, 2012. 
[2] C. A. Weirich and T. R. Miller, "Freshwater harmful algal blooms: Toxins and children's health," Current Problems in Pediatric and Adolescent Health Care, vol. 44, no. 1, pp. 2-24, 2014.

[3] P. K. Pandey, P. H. Kass, M. L. Soupir, S. Biswas, and V. P. Singh, "Contamination of water resources by pathogenic bacteria," AMB Express, vol. 4, no. 1, article no. 51, pp. 1-16, 2014.

[4] T. H. J. Niedermeyer, A. Daily, M. Swiatecka-Hagenbruch, and J. A. Moscow, "Selectivity and potency of microcystin congeners against OATP1B1 and OATP1B3 expressing cancer cells," PLoS ONE, vol. 9, article e91476, no. 3, 2014.

[5] M. Masikini, A. R. Williams, C. E. Sunday et al., "Label free poly(2,5-dimethoxyaniline)-multi-walled carbon nanotubes impedimetric immunosensor for fumonisin B1 detection," Materials, vol. 9, no. 4, article 273, 2016.

[6] M. Dettenkofer and R. C. Spencer, "Importance of environmental decontamination - a critical view," Journal of Hospital Infection, vol. 65, no. 2, pp. 55-57, 2007.

[7] R. J. McGray and P. Dineen, "Hospital testing of products and procedures for inanimate environmental decontamination. 1. The importance of recognizing environmental challenges.," Hospital Topics, vol. 53, no. 5, pp. 15-39, 1975.

[8] O. Tovide, N. Jaheed, N. Mohamed et al., "Graphenated polyaniline-doped tungsten oxide nanocomposite sensor for real time determination of phenanthrene," Electrochimica Acta, vol. 128, pp. 138-148, 2014.

[9] M. T. Amin, A. A. Alazba, and U. Manzoor, "A review of removal of pollutants from water/wastewater using different types of nanomaterials," Advances in Materials Science and Engineering, vol. 2014, Article ID 825910, 24 pages, 2014.

[10] E. Schax, M. Lönne, T. Scheper, S. Belkin, and J.-G. Walter, "Aptamer-based depletion of small molecular contaminants: A case study using ochratoxin A," Biotechnology and Bioprocess Engineering, vol. 20, no. 6, pp. 1016-1025, 2015.

[11] V. Pichon, F. Brothier, and A. Combès, "Aptamer-basedsorbents for sample treatment - A review," Analytical and Bioanalytical Chemistry, vol. 407, no. 3, pp. 681-698, 2015.

[12] A. Renaud De La Faverie, F. Hamon, C. Di Primo et al., "Nucleic acids targeted to drugs: SELEX against a quadruplex ligand," Biochimie, vol. 93, no. 8, pp. 1357-1367, 2011.

[13] C. Tuerk and L. Gold, "Systemic evolution of ligands by exponential enrichment: RNA ligands to bacteriophage T4 DNA polymerase," Science, vol. 249, no. 4968, pp. 505-510, 1990.

[14] A. D. Ellington and J. W. Szostak, "In vitro selection of RNA molecules that bind specific ligands," Nature, vol. 346, no. 6287, pp. 818-822, 1990.

[15] M. Blind and M. Blank, "Aptamer Selection Technology and Recent Advances," Molecular Therapy - Nucleic Acids, vol. 4, no. 1, article e223, 2015.

[16] B. A. Bukari, M. Citartan, E. S. Ch'ng, M. P. Bilibana, T. Rozhdestvensky, and T. Tang, "Aptahistochemistry in diagnostic pathology: technical scrutiny and feasibility," Histochemistry and Cell Biology, vol. 147, no. 5, pp. 545-553, 2017.

[17] W. Yoshida, K. Abe, and K. Ikebukuro, "Emerging techniques employed in aptamer-based diagnostic tests," Expert Review of Molecular Diagnostics, vol. 14, no. 2, pp. 143-151, 2014.

[18] M. Citartan, S. C. B. Gopinath, J. Tominaga, Y. Chen, and T.-H. Tang, "Use of UV-vis-NIR spectroscopy to monitor label-free interaction between molecular recognition elements and erythropoietin on a gold-coated polycarbonate platform," Talanta, vol. 126, pp. 103-109, 2014.
[19] M. Citartan, S. C. B. Gopinath, J. Tominaga, and T.-H. Tang, "Label-free methods of reporting biomolecular interactions by optical biosensors," Analyst, vol. 138, no. 13, pp. 3576-3592, 2013.

[20] M. Citartan, S. C. B. Gopinath, J. Tominaga, S.-C. Tan, and T.H. Tang, "Assays for aptamer-based platforms," Biosensors and Bioelectronics, vol. 34, no. 1, pp. 1-11, 2012.

[21] S. Y. Toh, M. Citartan, S. C. B. Gopinath, and T.-H. Tang, "Aptamers as a replacement for antibodies in enzyme-linked immunosorbent assay," Biosensors and Bioelectronics, vol. 64, pp. 392-403, 2014.

[22] M. P. Bilibana, A. R. Williams, C. Rassie et al., "Electrochemical aptatoxisensor responses on nanocomposites containing electro-deposited silver nanoparticles on poly(Propyleneimine) dendrimer for the detection of microcystin-LR in freshwater," Sensors (Switzerland), vol. 16, no. 11, article no. 1901, 2016.

[23] S. Wang, L. Zhang, S. Wan et al., "Aptasensor with expanded nucleotide using DNA nanotetrahedra for electrochemical detection of cancerous exosomes," ACS Nano, vol. 11, no. 4, pp. 3943-3949, 2017.

[24] Y. Jiang, M. Shi, Y. Liu et al., "Aptamer/AuNP biosensor for colorimetric profiling of exosomal proteins," Angewandte Chemie International Edition, vol. 56, no. 39, pp. 11916-11920, 2017.

[25] H. B. Seo and M. B. Gu, "Aptamer-based sandwich-type biosensors," Journal of Biological Engineering, vol. 11, no. 1, article 11, 2017.

[26] V.-T. Nguyen, Y. S. Kwon, and M. B. Gu, "Aptamer-based environmental biosensors for small molecule contaminants," Current Opinion in Biotechnology, vol. 45, pp. 15-23, 2017.

[27] M. Citartan, E.-S. Ch'ng, T. S. Rozhdestvensky, and T.-H. Tang, "Aptamers as the 'capturing' agents in aptamer-based capture assays," Microchemical Journal, vol. 128, pp. 187-197, 2016.

[28] C. Forier, E. Boschetti, M. Ouhammouch et al., "DNA aptamer affinity ligands for highly selective purification of human plasma-related proteins from multiple sources," Journal of Chromatography A, vol. 1489, pp. 39-50, 2017.

[29] A. Ruscito and M. C. DeRosa, "Small-molecule binding aptamers: Selection strategies, characterization, and applications," Frontiers in Chemistry, vol. 4, article 14, 2016.

[30] R. D. Jenison, S. C. Gill, A. Pardi, and B. Polisky, "Highresolution molecular discrimination by RNA," Science, vol. 263, no. 5152, pp. 1425-1429, 1994.

[31] M. Famulok and J. W. Szostak, "Stereospecific recognition of tryptophan agarose by in vitro selected RNA," Journal of the American Chemical Society, vol. 114, no. 10, pp. 3990-3991, 1992.

[32] M. Famulok, "Molecular recognition of amino acids by RNAaptamers: An L-citrulline binding RNA motif and its evolution into an L-arginine binder," Journal of the American Chemical Society, vol. 116, no. 5, pp. 1698-1706, 1994.

[33] S. Balamurugan, A. Obubuafo, S. A. Soper, and D. A. Spivak, "Surface immobilization methods for aptamer diagnostic applications," Analytical and Bioanalytical Chemistry, vol. 390, no. 4, pp. 1009-1021, 2008.

[34] G. Dong Huy, N. Jin, B.-C. Yin, and B.-C. Ye, "A novel separation and enrichment method of $17 \beta$-estradiol using aptameranchored microbeads," Bioprocess and Biosystems Engineering, vol. 34, no. 2, pp. 189-195, 2011.

[35] B. Chen, Q. Ye, K. Zhou, and Y. Wang, "Adsorption and separation of HCV particles by novel affinity aptamer-functionalized adsorbents," Journal of Chromatography B: Analytical Technologies in the Biomedical and Life Sciences, vol. 1017-1018, pp. 174181, 2016. 
[36] B. J. Sanghavi, J. A. Moore, J. L. Chávez et al., "Aptamerfunctionalized nanoparticles for surface immobilization-free electrochemical detection of cortisol in a microfluidic device," Biosensors and Bioelectronics, vol. 78, pp. 244-252, 2016.

[37] X. Hu, K. L. Tulsieram, Q. Zhou, L. Mu, and J. Wen, "Polymeric nanoparticle-aptamer bioconjugates can diminish the toxicity of mercury in vivo," Toxicology Letters, vol. 208, no. 1, pp. 6974, 2012.

[38] C. Pan, W. Wang, H. Zhang, L. Xu, and X. Chen, "In situ synthesis of homochiral metal-organic framework in capillary column for capillary electrochromatography enantioseparation," Journal of Chromatography A, vol. 1388, pp. 207-216, 2015.

[39] S. Lin, N. Gan, Y. Cao, Y. Chen, and Q. Jiang, "Selective dispersive solid phase extraction-chromatography tandem mass spectrometry based on aptamer-functionalized UiO-66-NH2 for determination of polychlorinated biphenyls," Journal of Chromatography A, vol. 1446, pp. 34-40, 2016.

[40] B. Madru, F. Chapuis-Hugon, E. Peyrin, and V. Pichon, "Determination of cocaine in human plasma by selective solidphase extraction using an aptamer-based sorbent," Analytical Chemistry, vol. 81, no. 16, pp. 7081-7086, 2009.

[41] R. Baçhor, A. Kluczyk, P. Stefanowicz, and Z. Szewczuk, "New method of peptide cleavage based on Edman degradation," Molecular Diversity, vol. 17, no. 3, pp. 605-611, 2013.

[42] S. E. Ross, S. D. Carson, and L. M. Fink, "Effects of detergents on avidin-biotin interaction," Biotechniques, vol. 4, no. 4, pp. 350354, 1986.

[43] M. Kim, H.-J. Um, S. Bang et al., "Arsenic removal from Vietnamese groundwater using the arsenic-binding DNA aptamer," Environmental Science and Technology, vol. 43, no. 24, pp. 93359340, 2009.

[44] G. Zakrzewska-Trznadel, "Advances in membrane technologies for the treatment of liquid radioactive waste," Desalination, vol. 321, pp. 119-130, 2013.

[45] J. Flouret, Y. Barré, H. Muhr, and E. Plasari, "Design and implementation of an intensified coprecipitation reactor for the treatment of liquid radioactive wastes," in Proceedings of the ASME 2013 15th International Conference on Environmental Remediation and Radioactive Waste Management, ICEM 2013, bel, September 2013.

[46] X. Hu, L. Mu, Q. Zhou, J. Wen, and J. Pawliszyn, "ssDNA aptamer-based column for simultaneous removal of nanogram per liter level of illicit and analgesic pharmaceuticals in drinking water," Environmental Science \& Technology, vol. 45, no. 11, pp. 4890-4895, 2011.

[47] L.-H. C. Hsieh, Y.-H. Weng, C.-P. Huang, and K.-C. Li, "Removal of arsenic from groundwater by electro-ultrafiltration," Desalination, vol. 234, no. 1-3, pp. 402-408, 2008.

[48] A. Clearfield, "Ion-exchange materials: Seizing the caesium," Nature Chemistry, vol. 2, no. 3, pp. 161-162, 2010.

[49] J. Kammerer, R. Carle, and D. R. Kammerer, "Adsorption and ion exchange: basic principles and their application in food processing," Journal of Agricultural and Food Chemistry, vol. 59, no. 1 , pp. 22-42, 2011.

[50] A. C. Hakonson-Hayes, P. R. Fresquez, and F. W. Whicker, "Assessing potential risks from exposure to natural uranium in well water," Journal of Environmental Radioactivity, vol. 59, no. 1, pp. 29-40, 2002.

[51] J. Kim, M. Y. Kim, H. S. Kim, and S. S. Hah, "Binding of uranyl ion by a DNA aptamer attached to a solid support," Bioorganic and Medicinal Chemistry Letters, vol. 21, no. 13, pp. 4020-4022, 2011.
[52] X. Hu, L. Mu, J. Wen, and Q. Zhou, "Immobilized smart RNA on graphene oxide nanosheets to specifically recognize and adsorb trace peptide toxins in drinking water," Journal of Hazardous Materials, vol. 213-214, pp. 387-392, 2012.

[53] L. Oziol and N. Bouaïcha, "First evidence of estrogenic potential of the cyanobacterial heptotoxins the nodularin- $\mathrm{R}$ and the microcystin-LR in cultured mammalian cells," Journal of Hazardous Materials, vol. 174, no. 1-3, pp. 610-615, 2010.

[54] L. C. Backer, S. V. McNeel, T. Barber et al., "Recreational exposure to microcystins during algal blooms in two California lakes," Toxicon, vol. 55, no. 5, pp. 909-921, 2010.

[55] C. L. A. Hamula, H. Zhang, L. L. Guan, X.-F. Li, and X. C. Le, "Selection of aptamers against live bacterial cells," Analytical Chemistry, vol. 80, no. 20, pp. 7812-7819, 2008.

[56] M. Y. Song, J. Jurng, Y.-K. Park, and B. C. Kim, "An aptamer cocktail-functionalized photocatalyst with enhanced antibacterial efficiency towards target bacteria," Journal of Hazardous Materials, vol. 318, pp. 247-254, 2016.

[57] Y. S. Kim, M. Y. Song, J. Jurng, and B. C. Kim, "Isolation and characterization of DNA aptamers against Escherichia coli using a bacterial cell-systematic evolution of ligands by exponential enrichment approach," Analytical Biochemistry, vol. 436, no. 1, pp. 22-28, 2013.

[58] S. Amaya-González, N. de-los-Santos-Álvarez, A. J. MirandaOrdieres, and M. J. Lobo-Castañón, "Aptamer-based analysis: A promising alternative for food safety control," Sensors (Switzerland), vol. 13, no. 12, pp. 16292-16311, 2013.

[59] Y. S. Kim, J. H. Niazi, Y. J. Chae, U.-R. Ko, and M. B. Gu, "Aptamers-in-liposomes for selective and multiplexed capture of small organic compounds," Macromolecular Rapid Communications, vol. 32, no. 15, pp. 1169-1173, 2011.

[60] J. A. Cruz-Aguado and G. Penner, "Determination of ochratoxin A with a DNA aptamer," Journal of Agricultural and Food Chemistry, vol. 56, no. 22, pp. 10456-10461, 2008.

[61] X. Yang, W. Kong, Y. Hu et al., "Aptamer-affinity column cleanup coupled with ultra high performance liquid chromatography and fluorescence detection for the rapid determination of ochratoxin A in ginger powder," Journal of Separation Science, vol. 37, no. 7, pp. 853-860, 2014.

[62] X. Wu, J. Hu, B. Zhu, L. Lu, X. Huang, and D. Pang, "Aptamertargeted magnetic nanospheres as a solid-phase extraction sorbent for determination of ochratoxin A in food samples," Journal of Chromatography A, vol. 1218, no. 41, pp. 7341-7346, 2011.

[63] K. Sefah, D. Shangguan, X. Xiong, M. B. O’Donoghue, and W. Tan, "Development of DNA aptamers using Cell-SELEX," Nature protocols, vol. 5, no. 6, pp. 1169-1185, 2010.

[64] E. Rouah-Martin, W. Maho, J. Mehta et al., "Aptamer-based extraction of ergot alkaloids from ergot contaminated rye feed," Advances in Bioscience and Biotechnology, vol. 05, no. 08, pp. 692-698, 2014.

[65] A. Davydova, M. Vorobjeva, D. Pyshnyi, S. Altman, V. Vlassov, and A. Venyaminova, "Aptamers against pathogenic microorganisms," Critical Reviews in Microbiology, vol. 42, no. 6, pp. 847-865, 2016.

[66] H. Sun, X. Zhu, P. Y. Lu, R. R. Rosato, W. Tan, and Y. Zu, "Oligonucleotide aptamers: New tools for targeted cancer therapy," Molecular Therapy - Nucleic Acids, vol. 3, article no. e182, 2014.

[67] S. Li, N. Chen, E. R. Gaddes, X. Zhang, C. Dong, and Y. Wang, "A Drosera-bioinspired hydrogel for catching and killing cancer cells," Scientific Reports, vol. 5, Article ID 14297, 2015. 
[68] Y. Zhang, H. Hong, and W. Cai, “Tumor-targeted drug delivery with aptamers," Current Medicinal Chemistry, vol. 18, no. 27, pp. 4185-4194, 2011.

[69] J. W. Lee, H. J. Kim, and K. Heo, "Therapeutic aptamers: Developmental potential as anticancer drugs," BMB Reports, vol. 48, no. 4, pp. 234-237, 2015.

[70] D. W. Drolet, L. S. Green, L. Gold, and N. Janjic, "Fit for the Eye: Aptamers in Ocular Disorders," Nucleic Acid Therapeutics, vol. 26, no. 3, pp. 127-146, 2016.

[71] D. Proske, S. Gilch, F. Wopfner, H. M. Schätzl, Ernst-L. Winnacker, and M. Famulok, "Prion-protein-specific aptamer reduces PrPSc formation," ChemBioChem, vol. 3, no. 8, pp. 717725, 2002.

[72] S. Li, N. Chen, Z. Zhang, and Y. Wang, "Endonuclease-responsive aptamer-functionalized hydrogel coating for sequential catch and release of cancer cells," Biomaterials, vol. 34 , no. 2 , pp. 460-469, 2013.

[73] L.-H. Lv, Y.-L. Wan, Y. Lin et al., "Anticancer drugs cause release of exosomes with heat shock proteins from human hepatocellular carcinoma cells that elicit effective natural killer cell antitumor responses in vitro," Journal of Biological Chemistry, vol. 287, no. 19, pp. 15874-15885, 2012.

[74] J. Gobbo, G. Marcion, M. Cordonnier et al., "Restoring Anticancer Immune Response by Targeting Tumor-Derived Exosomes with a HSP70 Peptide Aptamer," Journal of the National Cancer Institute, vol. 108, article djv330, no. 3, 2016.

[75] G. Fichet, E. Comoy, C. Dehen et al., "Investigations of a prion infectivity assay to evaluate methods of decontamination," Journal of Microbiological Methods, vol. 70, no. 3, pp. 511-518, 2007.

[76] S. J. Xiao, P. P. Hu, L. Q. Chen et al., "A Visual Dual-Aptamer Logic Gate for Sensitive Discrimination of Prion DiseasesAssociated Isoform with Reusable Magnetic Microparticles and Fluorescence Quantum Dots," PLoS ONE, vol. 8, no. 2, Article ID e53935, 2013.

[77] J. Wang, H. Shen, X. Hu et al., "A targeted "capture" and "removal" Scavenger toward multiple pollutants for water remediation based on molecular recognition," Advanced Science, vol. 3, no. 3, Article ID 1500289, 2015.

[78] Y. Nomura, S. Sugiyama, T. Sakamoto et al., "Conformational plasticity of RNA for target recognition as revealed by the 2.15 Å crystal structure of a human IgG-aptamer complex," Nucleic Acids Research, vol. 38, no. 21, pp. 7822-7829, 2010.

[79] A. D. Keefe, S. Pai, and A. Ellington, "Aptamers as therapeutics," Nature Reviews Drug Discovery, vol. 9, no. 7, pp. 537-550, 2010.

[80] S. Shigdar, J. Macdonald, M. O'Connor et al., "Aptamers as theranostic agents: modifications, serum stability and functionalisation," Sensors, vol. 13, no. 10, pp. 13624-13637, 2013.

[81] C. Wilson and A. D. Keefe, "Building oligonucleotide therapeutics using non-natural chemistries," Current Opinion in Chemical Biology, vol. 10, no. 6, pp. 607-614, 2006.

[82] N. M. Dean and C. Frank Bennett, "Antisense oligonucleotidebased therapeutics for cancer," Oncogene, vol. 22, no. 56, pp. 9087-9096, 2003.

[83] H. Y. Kong and J. Byun, "Nucleic acid aptamers: New methods for selection, stabilization, and application in biomedical science," Biomolecules and Therapeutics, vol. 21, no. 6, pp. 423-434, 2013.

[84] M. A. Campbell and J. Wengel, "Locked vs. unlocked nucleic acids (LNA vs. UNA): Contrasting structures work towards common therapeutic goals," Chemical Society Reviews, vol. 40, no. 12, pp. 5680-5689, 2011.
[85] S. Klußmann, A. Nolte, R. Bald, V. A. Erdmann, and J. P. Fürste, "Mirror-image RNA that binds D-Adenosine," Nature Biotechnology, vol. 14, no. 9, pp. 1112-1115, 1996.

[86] H. U. Goringer, A. Annette, F. Nicole, and H. Matthias, "PostSELEX chemical optimization of a trypanosome-specific RNA aptamer," Combinatorial Chemistry \& High Throughput Screening, vol. 11, no. 1, pp. 16-23, 2008.

[87] S. C. B. Gopinath, T. Lakshmipriya, Y. Chen, W.-M. Phang, and U. Hashim, "Aptamer-based 'point-of-care testing,' Biotechnology Advances, vol. 34, no. 3, pp. 198-208, 2016.

[88] M. Elimelech and W. A. Phillip, "The future of seawater desalination: energy, technology, and the environment," Science, vol. 333, no. 6043, pp. 712-717, 2011.

[89] H. Chen, S. Xie, H. Liang et al., "Generation of Biostable Laptamers against Achiral Targets by Chiral Inversion of Existing D-aptamers," Talanta, vol. 164, pp. 662-667, 2017.

[90] F. Lipi, S. Chen, M. Chakravarthy, S. Rakesh, and R. N. Veedu, "In vitro evolution of chemically-modified nucleic acid aptamers: Pros and cons, and comprehensive selection strategies," RNA Biology, vol. 13, no. 12, pp. 1232-1245, 2016.

[91] P. Ray and R. R. White, "Cell-SELEX Identifies a "sticky" RNA Aptamer Sequence," Journal of Nucleic Acids, vol. 2017, Article ID 4943072, 9 pages, 2017.

[92] M. McKeague, E. M. McConnell, J. Cruz-Toledo et al., "Analysis of In Vitro Aptamer Selection Parameters," Journal of Molecular Evolution, vol. 81, no. 5-6, pp. 150-161, 2015.

[93] C. Schulz, J. Hecht, A. Krüger-Genge, K. Kratz, F. Jung, and A. Lendlein, "Generating Aptamers Interacting with Polymeric Surfaces for Biofunctionalization," Macromolecular Bioscience, vol. 16, no. 12, pp. 1776-1791, 2016.

[94] D. J. Scoville, T. K. B. Uhm, J. A. Shallcross, and R. J. Whelan, "Selection of DNA Aptamers for Ovarian Cancer Biomarker CA125 Using One-Pot SELEX and High-Throughput Sequencing," Journal of Nucleic Acids, vol. 2017, Article ID 9879135, 9 pages, 2017.

[95] R. Ranjbar and M. S. Hafezi-Moghadam, "Design and construction of a DNA origami drug delivery system based on MPT64 antibody aptamer for tuberculosis treatment," Electronic physician, vol. 8, no. 2, pp. 1857-1864, 2016.

[96] P. W. K. Rothemund, "PHYS 307-DNA origami: Folding DNA to create nanoscale shapes and patterns," Abstracts of Papers of the American Chemical Society, vol. 234, 2007.

[97] P. W. K. Rothemund, "Folding DNA to create nanoscale shapes and patterns," Nature, vol. 440, no. 7082, pp. 297-302, 2006.

[98] S. M. Douglas, I. Bachelet, and G. M. Church, "A logic-gated nanorobot for targeted transport of molecular payloads," Science, vol. 335, no. 6070, pp. 831-834, 2012. 

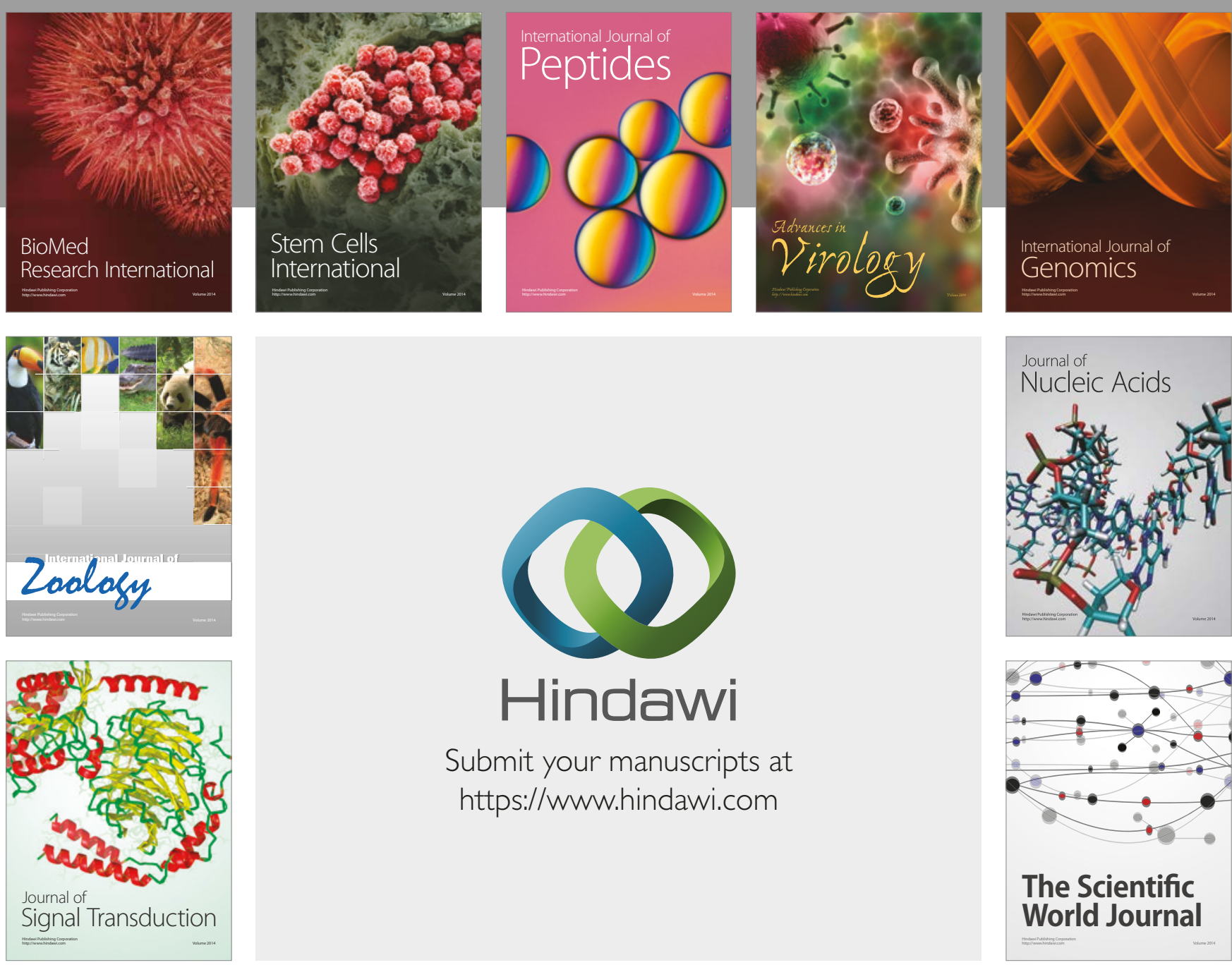

Submit your manuscripts at

https://www.hindawi.com
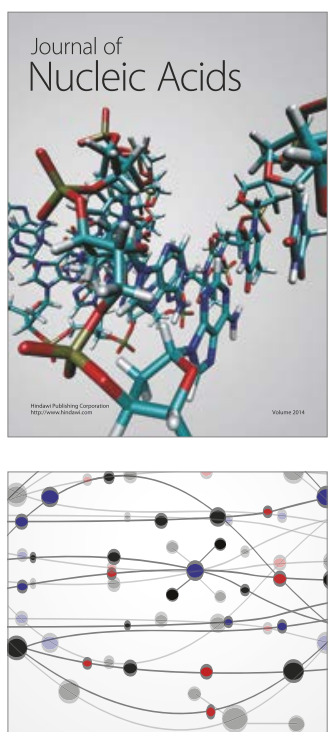

The Scientific World Journal

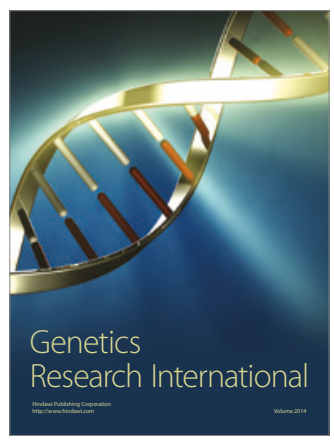

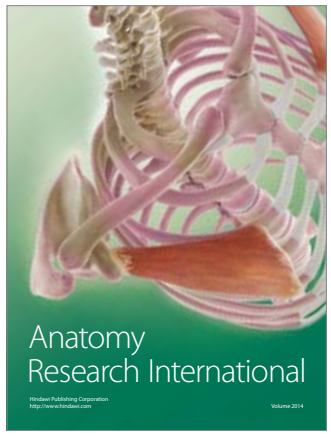

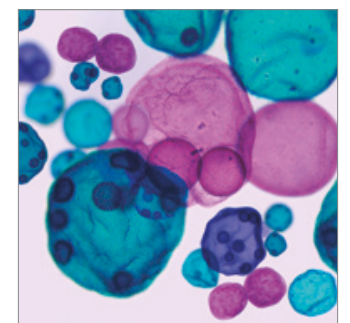

International Journal of Microbiology
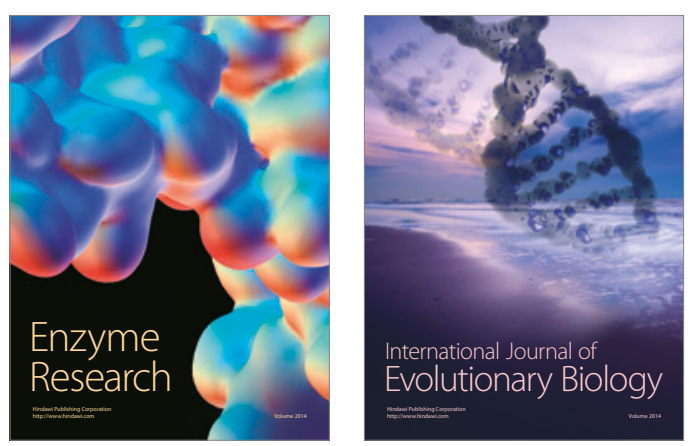
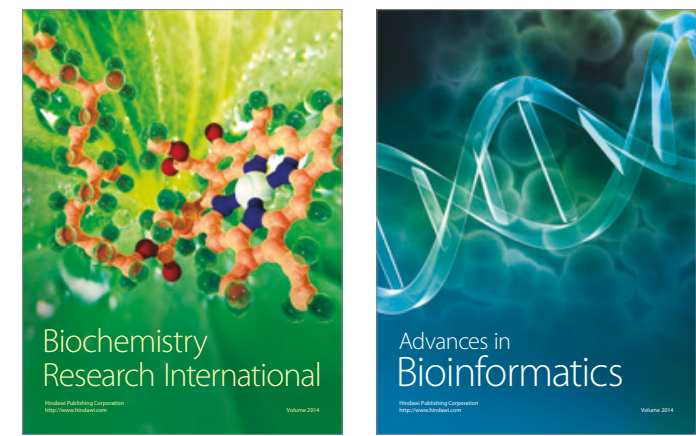

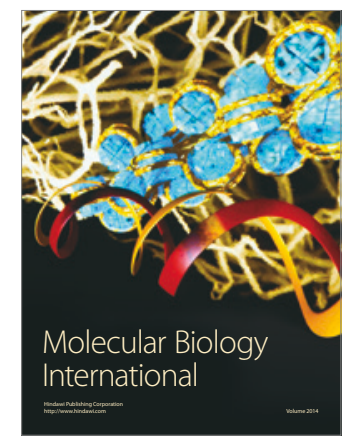

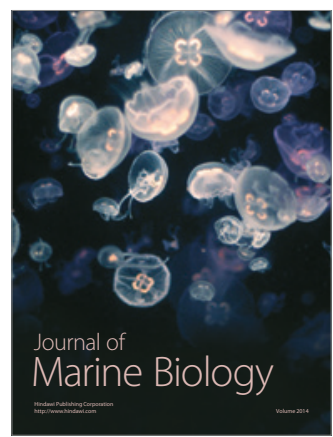

